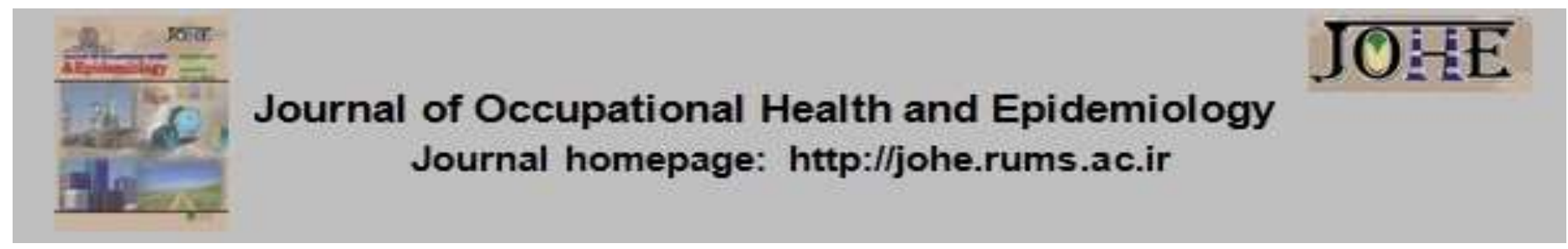

\title{
Prevalence and Vaccination Status of Hepatitis B among Healthcare Workers in Allied Hospital of Faisalabad: A Cross-Sectional Study, 2017-18
}

\author{
Mazhar Iqbal ${ }^{1 *}$, Allah Rakhia², Faiz Ahmed Raza ${ }^{3}$, Aisha Ambreen ${ }^{4}$, Obaid Anwar ${ }^{5}$ \\ 1- M.Phil in Biochemistry, Pakistan Health Research Council, Research Centre, Faisalabad Medical University (FMU), Faisalabad, \\ Pakistan. \\ 2- MSc in Microbiology, Pakistan Health Research Council, Research Centre, National Institute of Child Health (NICH), Karachi, \\ Pakistan. \\ 3- PhD in Microbiology, Pakistan Health Research Council, Research Centre, Fatima Jinnah Medical University (FJMU), Lahore, \\ Pakistan. \\ 4- PhD in Biochemistry, Biochemistry Department, Faisalabad Medical University, Faisalabad, Pakistan. \\ 5- M.Phil in Pharmacology, Pharmacology Department, Faisalabad Medical University, Faisalabad, Pakistan.
}

\section{Citation: Iqbal M, Rakhia A, Ahmed Raza F, Ambreen A, Anwar O. Prevalence and Vaccination Status of Hepatitis B among Healthcare Workers in Allied Hospital of Faisalabad:

\section{Article Info}

\section{${ }^{*}$ Corresponding author: \\ Mazhar lqbal, \\ E-mail: \\ mazhar.iqbal174@gmail.com}

\section{Article history \\ Received: Dec 2019 \\ Accepted: June 2020}

10.29252/johe.8.4.185

Print ISSN: 2251-8096 Online ISSN: 2252-0902

Peer review under responsibility of Journal of Occupational Health and Epidemiology

\section{Abstract}

Background: The vaccination status of HCWs working in Pakistani hospitals against the hepatitis $B$ virus is poorly known. This study aims to assess the vaccination status of hepatitis B among HCWs in Allied Hospital of Faisalabad.

Materials \& Methods: This cross-sectional study was conducted from July 2017 to June 2018. Two groups of HCWs were included in the study. Group 1 consisted of doctors and nurses at different wards of the hospital, and group 2 included final year undergraduate and nursing students. A predesigned form was administered to record information regarding their demographic characteristics and history of vaccination. Next, about $5 \mathrm{ml}$ of blood was taken from each participant to check HBsAg. Data were entered and analyzed in SPSS V16.0 by descriptive statistics and the chi-square test.

Results: From total $300 \mathrm{HCWs}, 222(74 \%) \mathrm{HCWs}$ were female and $78(26 \%)$ of them were male. The age of the participants was between 20-25. In addition, 135 (45\%) HCWs were fully vaccinated, 36 (12\%) HCWs were partially vaccinated, and $129(43 \%)$ HCWs were never vaccinated against hepatitis B. $59.7 \%$ of vaccination cases were found in doctors followed by $49.2 \%$ and $26.9 \%$ in students and nurses, respectively. The major reason for not being vaccinated was lack of time in 93 (63.7\%) HCWs.

Conclusion: Despite existing recommendations and higher prevalence rates of hepatitis $\mathrm{B}$ in high-risk groups, about $40 \%$ of the HCWs were not vaccinated either due to unawareness or carelessness.

Keywords: Healthcare Workers, Hepatitis B Virus, Hepatitis B Surface Antigen

\section{Introduction}

Hepatitis B is a virus that attacks the liver, which results in acute or chronic infections [1]. The global rate of $\mathrm{HBV}$ infection is high in healthcare workers (HCWs) due to occupational exposure [2]. According to the World Health Organization (WHO), 3 million HCWs experience percutaneous contact with blood-borne pathogens every year, out of which 2 million HCWs being exposed to the hepatitis $B$ virus [3]. Hepatitis $B$ vaccination is mandatory, and universal vaccination has been recommended in all countries with special recommendations for healthcare workers since 1982 [4]. However, global vaccination coverage is still unsatisfactory [5]. Unvaccinated healthcare workers are the potential sources of not only getting infected with the hepatitis $B$ virus but also in some cases transmitting the infection to 
patients. The global ratio of unvaccinated HCWs is high regardless of their knowledge about possible risks of HBV infection. The results of research on $H B$ vaccination status vary in different countries. Studies in South Africa, Pakistan, Sweden, Turkey, and France showed that $19.9 \%, 37.2 \%, 39.8 \%$, $55.8 \%$, and $93 \%$ of HCWs were vaccinated, respectively [6].

In every country, acquiring the knowledge of people's attitude towards hepatitis B vaccination as well as its coverage and effectiveness in HCWs is a tough challenge, which should be the basis for healthcare policies. Data from Pakistan in this field are not sufficient. There are a small number of studies conducted in Pakistan on the prevalence, status, and awareness of hepatitis B as well as the approach to basic infection control practices. In implementation of effective infection control programs in the healthcare field, basic data will help find the precise direction because the prevalence of this disease and HCWs' attitude vary from place to place.

Faisalabad is the third most populated city of Pakistan, and Allied Hospital is the primary teaching hospital of Punjab Medical College with the capacity of approximately 1300 beds. The current study was conducted to evaluate the prevalence and vaccination status of hepatitis B among healthcare workers in Allied Hospital, Faisalabad, to find the reasons why they were not vaccinated or not given vaccination in the past.

\section{Materials and Methods}

This cross-sectional study was conducted in one year from July 2017 to June 2018. It was conducted at Pakistan Health Research Council (PHRC), Research Centre, Punjab Medical College, Faisalabad. The study sample included 300 healthcare workers divided into two groups. Group 1 consisted of all final year undergraduate and nursing students without any work experience. Group 2 included doctors and nurses from wards of medicine, surgery, gynecology, and emergency, with a minimum of 2 years of experience. Ethical approval was obtained for this study from the
Ethical Review Committee (ERC), Punjab Medical College, Faisalabad, before starting it. In addition, informed consent forms were taken from all participants in this research. A predesigned form was administered to the participants to record information about their demographic characteristics, past history, family history, vaccination status, and $\mathrm{HBsAg}$ status before vaccination. In case vaccination was incomplete, they were supposed to state possible reasons for not being vaccinated. Next, about $5 \mathrm{ml}$ of their blood was taken to test HBsAg (hepatitis B surface antigen). The serum was tested for $\mathrm{HBsAg}$ antibodies with a rapid diagnostic strip by Determine $^{\mathrm{TM}}$ HBsAg (Abbott Laboratories) according to the manufacturer's instructions. Data were entered and analyzed in SPSS V16.0 by descriptive statistics and the chi-square test.

\section{Results}

Out of $300 \mathrm{HCWs}, 222$ (74\%) HCWs were female, and $78(26 \%)$ HCWs were male. The majority of the cases aged 20-25. In addition, the majority of the participants were students $(130,43.3 \%)$ followed by nurses $(93,31.0 \%)$ and doctors $(77$, $25.6 \%) .95$ (31.7\%) individuals were from the department of surgery, $72(24 \%)$ individuals were from the MBBS class, 52 (17.3\%) individuals were from the department of medicine, 50 (16.7\%) individuals were from the nursing class, followed by 31 (10.3) individuals from the department of gynecology. Out of $300 \mathrm{HCWs,} 217$ (72.3\%) individuals were aware of their HBsAg status at the time of the study. Only $6(2 \%)$ participants had a past history of jaundice. In 36 (12\%) participants, some of their family members had experienced jaundice in the past. Out of 300 cases, only 135 $(45 \%)$ cases were fully vaccinated, i.e. received three doses of the hepatitis B vaccine in the past, $36(12 \%)$ cases were partially vaccinated (one or two doses), and 129 (43\%) cases were never vaccinated against hepatitis $B$. In majority of the cases, vaccination was given within the last 5 years, and only 31 cases were vaccinated more than 15 years ago.

Table 1. Mean HCWs' Vaccination Status

\begin{tabular}{|c|c|c|c|c|c|}
\hline & & $\begin{array}{c}\text { Fully Vaccinated } \\
135(45.0 \%)\end{array}$ & $\begin{array}{c}\text { Partially Vaccinated } \\
36(12)\end{array}$ & $\begin{array}{c}\text { Not Vaccinated } \\
129(43.0)\end{array}$ & $\begin{array}{c}\text { Total } \\
300\end{array}$ \\
\hline \multirow{5}{*}{$\begin{array}{c}\text { Place of } \\
\text { Working/Studying }\end{array}$} & Nursing School & $11(22.0)$ & $4(8.0)$ & $35(70.0)$ & 50 \\
\hline & Medical College & $49(68.1)$ & $9(12.5)$ & 14(19.4) & 72 \\
\hline & Medicine & 18(34.6) & $14(26.9)$ & $20(38.5)$ & 52 \\
\hline & Surgery & $40(42.1)$ & $6(6.3)$ & $49(51.6)$ & 95 \\
\hline & Gynecology & $17(54.8)$ & $3(9.7 \%)$ & $11(35.5)$ & 31 \\
\hline \multirow{3}{*}{ Department } & Students & $64(49.2)$ & $15(11.5)$ & $51(39.2)$ & 130 \\
\hline & $\begin{array}{c}\text { Doctors (MOs, } \\
\text { HOs, PGs,) }\end{array}$ & $46(59.7 \%)$ & $14(18.2)$ & $17(22.1 \%)$ & 77 \\
\hline & Nurses & $25(26.9)$ & $7(7.5)$ & $61(65.6)$ & 93 \\
\hline
\end{tabular}


According to the HCWs' vaccination details, the maximum vaccination rate among the fully vaccinated individuals belonged to doctors with 46 $(59.7 \%)$ out of 77 individuals, who were fully vaccinated, followed by students with 64 (49.2\%) students out of 130 , and 25 nurses (26.9\%) out of 93. 40 (42.1) participants out of 95 from the department of surgery were vaccinated. The related details are given in Table 1.
Reasons for not having been vaccinated included being unaware in $14(9.6 \%)$ cases, regarding it unimportant in $11(7.5 \%)$ cases, being afraid of needles in $28(19.2 \%)$ cases, and lack of time in 93 $(63.7 \%)$ of cases. Among the fully vaccinated HCWs, only 18 (10.7) participants checked their antibody titer after completing all three doses (Table 2).

Table 2. Vaccination Details in the Past

\begin{tabular}{|c|c|c|c|}
\hline & & Frequency & Percentage \\
\hline \multirow{3}{*}{ Status of vaccination } & 1 shot & 8 & 5.3 \\
\hline & 2 shots & 28 & 16.4 \\
\hline & 3 shots & 134 & 78.4 \\
\hline \multirow{4}{*}{ Duration of vaccination } & Less than 5 years & 95 & 57.1 \\
\hline & 5 to 9 years & 24 & 14.6 \\
\hline & 10 to 14 years & 14 & 8.5 \\
\hline & More than 15 years & 31 & 18.9 \\
\hline \multirow{2}{*}{$\begin{array}{l}\text { Did you check antibody } \\
\text { status after vaccination? }\end{array}$} & Yes & 18 & 10.7 \\
\hline & No & 150 & 89.3 \\
\hline
\end{tabular}

\section{Discussion}

Healthcare workers are at a higher risk of getting infected with hepatitis B through professional exposure to blood and infectious body fluids. HCWs, working among infectious people, must be required to have effective sero-protection against hepatitis $B$ through vaccination.

The current study showed that $45 \%$ of the HCWs were fully vaccinated against the hepatitis $B$ virus and received three doses of the vaccine; however, $12 \%$ of them were partially vaccinated, and $43 \%$ of them were never vaccinated. According to the $\mathrm{WHO}$, the rate of $\mathrm{HBV}$ vaccination among $\mathrm{HCWs}$ in developing countries ranges from 18 to $39 \%$, and it ranges from 67 to $79 \%$ in developed countries [7]. The results of this study showed a lower vaccination rate than other studies conducted in Pakistan. A study conducted on HCWs in two university hospitals in Sindh Province revealed that only $64 \%$ of $\mathrm{HCW}$ sere vaccinated [8]; likewise, a study conducted in Abbottabad City showed $48 \%$ of HCWs had a history of vaccination. The variation in vaccination coverage is unsatisfactory because the vaccination rate should have been increased due to the growing knowledge about the problem over time. The vaccination rate in Pakistan is lower than its neighboring country India where the vaccination rate is $78 \%$ [9]; in the same vein, it is lower than that of Iran and Saudi Arabia with the vaccination rate of $71.7 \%[10,11]$. Possible reasons for this difference could be the variation in the study settings where HCWs receive appropriate vaccines and work in a better clinical setting.
The results of the present study showed that only $18(10.7 \%)$ participants checked their antibody titers after completing all three doses. This could be resulted from the fact that in resource-limited countries, the cost of determining anti-HBs titers is higher than that of receiving HBV vaccines [12]. There were 129 (43\%) unvaccinated respondents in the current study. The HCWs' approach to their own protection against hepatitis $B$ indicates the carefree attitude among people working in the health sector. The major reason reported for not having been vaccinated was lack of time $(63.7 \%)$, which could be due to the HCWs' busy schedules. Other reasons included fear of needle $(19.2 \%)$, unawareness $(9.6 \%)$, and not attaching importance to vaccination (7.5\%).

Among different groups of HCWs, doctors were found to have the highest vaccination percentage of $59.7 \%$ followed by students and nurses by $49.2 \%$ and $26 \%$, respectively. This result is consistent with the study conducted in Mumbai in which the maximum vaccination rate was found in postgraduate residents followed by medical students [13]. This indicates the education level makes the difference; in other words, the higher the education level is, the more the awareness and the better the vaccination status will be. A relatively higher rate of vaccination was observed in this study among HCWs working in the department of surgery. Direct exposure to patients' blood and body fluids might have led to the greater awareness of the HBV vaccine among HCWs in this field. The relatively low rate of vaccination among HCWs working in the department of 
internal medicine stresses the need for raising the awareness of the transmission risk and promoting vaccination in this group. In addition, the results showed that more than $50 \%$ of the cases were vaccinated within the past 5 years, which indicates the increasing trend of $\mathrm{HB}$ vaccination over time. This could be due to either an increase in awareness through media campaigns or greater acceptance among the HCWs.

The main limitation of this study was its dependence on self-reported $\mathrm{HB}$ vaccination status as well as reliance on only HBsAg. However, vaccination was not given to unvaccinated participants due to limited resources. Future studies should be conducted so as to vaccinate unvaccinated HCWs.

\section{Conclusion}

The results of the present study showed that a large number of HCWs in Faisalabad were not vaccinated. Thus, similar studies are required to be done to assess conditions in other tertiary referral hospitals at provincial level. It is recommended that institutions formulate policies of measuring hepatitis B immune status among HCWs upon their entry. They should also provide free HBV vaccines to all HCWs who are partially vaccinated or unvaccinated.

\section{Acknowledgement}

We would like to express our sincere gratitude to Pakistan Health Research Council (PHRC) for providing the grant for carrying out this study. We are also thankful to the staff at the PHRC Research Centre, Faisalabad, for their cooperation, especially to Mr. Shahid Mahmood and Mr. Liaqat Ali, for having collected data and blood samples in this study.

Conflict of interest: None declared.

\section{References}

1. Merican I, Guan R, Amarapuka D, Alexander MJ, Chutaputti A, Chienet RN, et al. Chronic hepatitis B virus infection in Asian countries. J Gastroenterol Hepatol 2000; 15(12):1356-61.

2. Topuridze M, Butsashvili M, Kamkamidze G, Kajaia M, Morse D, McNutt LA, et al. Barriers to hepatitis $B$ vaccine coverage among healthcare workers in the Republic of Georgia: An international perspective. Infect Control Hosp Epidemiol 2010; 31(2):158-64.
3. Vaz K, McGrowder D, Alexander-Lindo R, Gordon L, Brown P, Irving R. Knowledge, awareness and compliance with universal precautions among health care workers at the University Hospital of the West Indies, Jamaica. Int J Occup Environ Med 2010; 1(4):171-81.

4. Simard EP, Miller JT, George PA, Wasley A, Alter MJ, Bell BP, et al. Hepatitis B vaccination coverage levels among healthcare workers in the United States, 2002-2003. Infect Control Hosp Epidemiol 2007; 28(7):783-90.

5. Mahoney FJ, Stewart K, Hu H, Coleman P, Alter $M J$, et al. Progress toward the elimination of hepatitis B virus transmission among health care workers in the United States. Arch Intern Med 1997; 157(22):2601-5.

6. Abeje G, Azage M. Hepatitis B vaccine knowledge and vaccination status among health care workers of Bahir Dar City Administration, Northwest Ethiopia: a cross sectional study. BMC Infect Dis 2015; 15(1):30.

7. Abebaw T-A, Aderaw Z, Gebremichael B. Hepatitis B virus vaccination status and associated factors among health care workers in Shashemene Zonal Town, Shashemene, Ethiopia: a cross sectional study. BMC Res Notes 2017; 10(1):260.

8. Memon MS, Ansari S, Nizamani R, Khathri NK, Mirza MA, Jafri W. Hepatitis B vaccination status in health care workers of two university hospitals. Journal of Liaquat University of Medical and Health Sciences 2007; 6(2):48-51.

9. Dafei M, Sarin ShK, Kannan AT, Agrawal K, Garg S, Agrawal K, et al. Seroprevalence of blood borne pathogens among health care workers and their hepatitis $B$ vaccination status in tertiary care hospitals in India. Pharm Lett 2017; 9(1):142-52.

10. Amini-Ranjbar S, Motlagh ME. Hepatitis B vaccination coverage among Iranian medical students and nursing staff. Am J Appl Sci 2008; 5(6):747-9.

11. Panhotra BR, Saxena AK, Al-Hamrani HA, AlMulhim A. Compliance to hepatitis $B$ vaccination and subsequent development of seroprotection among health care workers of a tertiary care center of Saudi Arabia. Am J Infect Control 2005; 33(3):144-50.

12. Bilounga Ndongo $C$, Eteki L, Siedner M, Mbaye $\mathrm{R}$, Chen J, Ntone $\mathrm{R}$, et al. Prevalence and vaccination coverage of Hepatitis $B$ among healthcare workers in Cameroon: A national seroprevalence survey. J Viral Hepat 2018; 25(12):1582-7.

13. Shah DK, Jain SS, Khot $A A$, Gharat $A R$, Rajadhyaksha GC, Rathi PM. Low prevalence of hepatitis $B$ and $C$ infections among the healthcare workers despite low vaccination coverage for hepatitis B in Mumbai. Indian Journal of Medical Sciences 2017; 69(1):8-12. 